This is an Accepted Manuscript of an article published by Taylor \& Francis in Journal of Health Care Chaplaincy on 09/11/17, available online:

http://www.tandfonline.com/doi/full/10.1080/08854726.2017.13 86269 


\title{
Expressions of Prayer in Residential Care Homes
}

\author{
Sheryl Reimer-Kirkham \\ Trinity Western University, Langley, British Columbia, Canada \\ Sonya Sharma \\ Kingston University London, Kingston upon Thames, Surrey, United Kingdom \\ Brenda Smith, Kelly Schutt and Kyla Janzen \\ Trinity Western University, Langley, British Columbia, Canada
}

Although the value of spiritual care in the care of older adults is supported by research, few studies have focused specifically on prayer in residential care settings. This ethnographic study with fifteen chaplains and administrators in eleven residential care homes involved analyses of walking interviews and research diaries. Findings revealed the spaces in which prayer happens and the forms it takes. The identities of chaplains-their own spiritual practices, religious beliefs, and positioning within the facility - shaped their dis/comfort with prayer and how they located prayer within public and private spaces. Where organizational leadership endorsed the legitimacy of chaplaincy services, prayer was more likely to be offered. Even in these circumstances, however, religious diversity and questions about secularism left chaplains ambivalent about the appropriateness of prayer. The results demonstrate the relevance of religion and spirituality to residential care, and illustrate how prayer functions as an opportunity for connection and understanding.

Keywords older adults, prayer, residential care homes, spiritual care

Societies today are often described as religiously and spiritually diverse, with varying degrees of religious affiliation and expressions of personalized spiritualities. Global migration adds diversity, with diaspora in new lands typically maintaining links through religious identities and networks to the communities from which they came (Davie, 2013). At the same time, increasing numbers are indicating "no religion" on census surveys, in Canada and elsewhere (National Household Survey (NHS), 2011). These trends demonstrate the effect of migration and globalization on the relationship between religion and secularization, with postmodernity structuring a secular ethos in some segments of society, and sacralization in others. In our program of research on the negotiation of plurality in Canadian hospital and home health settings, we found prayer by patients, volunteers and staff to both support and challenge normative Christian practices and the secularity associated with healthcare. Acts of prayer had the capacity to bridge and reinforce religious differences between individuals and groups, and disrupt institutionalized schedules (Sharma, Reimer-Kirkham, \& Cochrane, 2013). In this paper, we report on an ethnographic study that extended this earlier research by exploring the expressions of prayer in residential care homes.

Our focus on prayer stems from the claim that prayer is the most vital activity on which all other religious practices depend; in the words of William James: "prayer is the very soul and essence of religion ... prayer is religion in act" (James, 1890/1950). The study of prayer illuminates the interface among religion, spirituality, and the public domain in that it is a phenomenon that seems to be characteristic not only of participants in every religion, but also those who do not identify with traditional religions or who may position themselves as "nones" (Drescher, 2016). In Canada, a recent poll found that $86 \%$ of respondents participated in some form of prayer in the last year (Angus Reid Institute, 2016). Along with its widespread practice and its valuable focus in understanding how people live their religion, spirituality, or beliefs, prayer "puts people in touch with the symbolic universe that sustains the believer in a life of faith" (Giordan \& Woodhead, 2013, p. 1). Sharp (2012) argues that prayer is "fundamentally a social interaction, or interaction between two or more actors," (p. 573) and can therefore be understood as a social psychological phenomenon, mimicking 
human social interactions, and influencing social action. He recommends further research to better understand the social dimensions of prayer.

Health research on prayer tends toward the instrumental effects of prayer, such as how prayer promotes healing or strengthens coping (Ai, Ladd, Peterson, Shearer, \& Koenig, 2010; Boelens, Reeves, Replogle, \& Koenig, 2009). A review of scholarly literature shows a small body of literature on prayer in residential care homes, as well as studies on spiritual care in the case of older adults, especially those with dementia (who are more likely to be in residential care homes). Smith (2008) studied prayer as an intervention for agitation in residential care home residents with dementia, and found a higher reported quality of life for those who participated in prayer, similar to the findings of Worcester (2008). Hill and Pargament (2003) found that various aspects of religious involvement, including prayer, might directly or indirectly buffer against cognitive decline through enhancing positive psychological feelings such as optimism and happiness. Similarly, in their review of spiritual nursing interventions for older adults with dementia, Ennis and Kazer (2013) reported the importance of spiritual rituals such as prayer, noting that prayer can restore a sense of control and connection, and also provide comfort and calm. Agli, Bailly, and Ferrand (2015), in a systematic review of 51 articles, reported improved health outcomes when spiritual care was provided for persons with dementia.

Along with studies on health outcomes of prayer, a few studies relate to contextual or social dimensions of prayer and older adults. Hayward and Krause (2013), in their study of prayer practices during older adulthood, found that prayer increased during the course of older adulthood, with prayers that were more mature in content (i.e., prayer for others and that God's will would come about), although prayers for material goods also increased. They conclude that more research is needed to place these findings in context. In their study exploring the impact of race differences on prayer among older adults, Krause and Chatters (2005) noted that the most frequent type of prayer in their subsample of older blacks was prayer for "God's will to be done," while older whites more frequently offered prayers of thanksgiving (p. 40). The authors explained that these differences demonstrate the social structural influences on prayer, arguing that people who feel disadvantaged are likely to look to religion for "compensation" by surrendering control of their circumstances to God, whereas those with greater wealth are likely to express more gratitude. Krause's earlier research (Krause, Chatters, Meltzer, \& Morgan, 2000) found that older adults valued praying in groups as they perceived enhanced social connection as a result that benefitted both those praying for others and those prayed for. We did not locate any studies that examined the social relations of prayer in residential care settings, although studies from Canada, Norway, Netherlands, United States, and the United Kingdom show that people with dementia were less likely to receive spiritual support (Carr, Hicks-Moore, \& Montgomery, 2011; Daaleman, Williams, Hamilton, \& Zimmerman, 2008; Gijsberts, vander Steen, Muller, Hertogh, \& Deliens, 2013; Ødbehr, Kvigne, Hauge, \& Danbolt, 2015; Sampson, Gould, Lee, \& Blanchard, 2006). Based on this 125 review of the literature, a gap exists as to the expression of prayer in residential care settings, particularly in regard to the social relations of prayer.

\section{STUDY PURPOSE AND OBJECTIVES}

This project explored the ways that prayer is manifest - whether embraced, tolerated, or resisted - in residential care homes, and how institutional and social contexts shaped how prayer is understood and enacted. Objectives were to: (1) examine how prayer transcends and/or heightens difference by connecting and/or distancing individuals; (2) analyze how prayer transgresses institutional routines in the everyday, by examining how patients, staff and volunteers navigate regulated hospital schedules to meet needs for prayer; (3) explore situations in which prayer might enact institutionalized power or a governmentality of religion; and (4) examine how acts of prayer transgress the secularity of public spaces, to gain insight into the expression of religion in public institutions. 


\section{METHODS}

Interpretive description (Thorne, 2016), using ethnographic data collection methods, was selected for its ability to uncover how social processes shape the everyday expression of prayer in residential care homes. Specifically, interpretive description is well suited to applied research that seeks practice applications and that seeks to describe and interpret a phenomenon through the lens of those who live it (Thorne, Reimer-Kirkham, \& MacDonaldEmes,1997). Ethical approval was obtained from appropriate Research Ethics Boards. We conducted repeat in-depth interviews with chaplains: an initial interview to establish rapport and introduce the project; a second interview to visit spaces in the residential care home where prayer occurred took the form of a "walking interview" and a third interview to discuss chaplains' recommendations in more detail. Walking interviews strengthened the ethnographic nature of data collection, whereby participants had more control over the content of the interview conversation, and chose what they wished to show the researchers to best typify their reality (Clark, 2010). In addition to the interviews and observations, we asked chaplains to keep a research diary to describe how they enacted prayer and the relationships and contexts in which prayer happened. Participants had their own ideas about what diary-keeping entailed and varied in types of reflection from more intimate entries to more straightforward reporting of events (Elliot, 1997). We also interviewed administrators to gain a better picture of the institutional context of prayer.

Data collection, management, and analysis occurred concurrently. As data were obtained, they were transcribed, closely read, and initial jottings made. The team discussed the first two interviews and created a list of codes to assign to the meaning units we identified in the transcripts. As an initial code book and conceptual structure was established, further data collection was undertaken to clarify, verify, and expand it to reach data saturation. NVivo a software program for qualitative data, we compared data across interviews and codes, and clustered codes into code categories with exemplars. Code categories were further refined and emergent themes were generated. In this way, evolving levels of thematic analysis was completed by moving in between the whole and the specific (Thorne, 2016).

\section{Sample}

Recruitment involved a letter of invitation sent to chaplains affiliated with an association that represents residential care homes overseen by faith groups (e.g., Jewish, Mennonite, Lutheran, Baptist, Catholic). Toward the end of the study, we purposively recruited four additional participants from three publicly-administered sites to offer further variability to our data. The sample consisted of 15 participants from eleven British Columbian residential care settings. Of these, eleven were chaplains, and four were administrators who oversaw spiritual care services. Participants were mainly of White ethnicities, and two were from Filipino and First Nations backgrounds, respectively. The majority self-identified as Christian (9 of 15); four were male, eleven were female.

\section{RESULTS}

Data analysis revealed that study participants shared a general understanding of prayer as communication with a higher power (whether God, a "divine entity" or Creator), but prayer itself was enacted in many different forms and contexts. We present three themes derived from the data: prayer in the day-to-day; organizational support of prayer; and the social contexts that shape prayer. The identity of the chaplain was important to how they enacted prayer in the day-to-day, and prayer was mediated by both the institution and society. In these ways, prayer was a social practice.

\section{Prayer in the Day-to-day}

The chaplains and administrators who participated in the study spoke of how prayer was intertwined with the day-to-day routines of institutionalized care for the elderly. 
Descriptions ANd EXPREsSions of Prayer

Participants described prayer as the simultaneous engagement between human experience and sacred dimensions, done in an effort to transcend the ordinary world. A chaplain commented: "I remind staff, 'I'm praying for you'. They know I'm conscious that they have a need and I'm not ignoring it, I am taking it to the highest power there is" (P7|S5). In this quote, we see bridging between the everyday - "having a need" - with the transcendent - "the highest power." Another participant described prayer as "a form of confession to God" (P1|S1). Confession could be understood as acknowledging everyday circumstances, be they about loss or gratitude. Chaplains perceived such prayers as humanizing and affirming personhood, given some residents' social isolation and cognitive decline. Most chaplains described the common referent of prayer as "God," although one chaplain described prayer as nontheistic, "it could be nature, it could be whatever" (P1|S1). For others, "it's more cultural than it is spiritual, but it still has the effect of taking one outside of their own existence" (P1|S1). These examples demonstrate no singular description of prayer. Prayer and everyday life in residential care were co-constituted.

This led us to consider how expressions of prayer were shaped by and inserted into institutional routines. Chaplains were creative in working prayer into the schedules of care. Prayer took many forms, some of them formal and ritualized, and others informal and spontaneous. The most common formal prayers occurred during religious services and at mealtimes (e.g., grace). Informal prayers were more likely to be unplanned and unscripted (e.g., praying in soft tones at a bedside, or the praying silently for residents while walking down a hallway), and reflected the value placed on one-to-one relationships. The majority of prayer described by chaplains was intercessory (i.e., praying on behalf of residents and staff), often with affirmations of faith and expressions of praise and worship. Regardless of the form, there was consensus that prayer was a very important aspect of chaplaincy services.

\section{ReLATIONALITY AND EMOTIONALITY}

Participants shared the view that prayer was best expressed in the context of relationships they formed with residents. One participant said: "everything else is secondary to the relational component. It's creating a feeling in the home of our residents as people and not just the condition they are in" (P1|S1). Prayer was often intimate, personal, requiring discernment from chaplains. Emotions were embedded in relational aspects of prayer, depicted in this commentary:

A lot of people have never been prayed for. They've been in a church where someone is praying but they've never been prayed for as an individual. They begin to weep ... this might be the first time in their lives they've felt that presence of God and it's overwhelming for them. (P9|S6)

The emotional dimension of prayer was also experienced by participants who told of the emotional effort it took to offer prayer, dependent on things such as one's energy and frame of mind. One chaplain wrote in her research diary:

Lack of emotional energy, worrying about what people think, becoming too focused on all the tasks I have to do (and therefore having no time left all make it less likely that I will participate in prayer with the residents. (P2|S2)

In this excerpt, the chaplain refers to the emotional labor that could be part of their work. It is "one part of a distinctly patterned yet invisible emotional system-a system composed of individual acts of 'emotion work,' social 'feeling rules,' and a great variety of exchanges between people in private and public life" (ix-x: Hochschild, 2003).

EMBODIMENT OF PRAYER

The embodiment of prayer meant engaging the full person - prayer was bound up with the 
body. Whether prayer was spoken or unspoken, there was a sense that it was mutually shaped by the body's position, movement, and condition. For the frail elderly, embodied prayer could mean the chaplain assisted with positioning the resident or themselves in a way to facilitate prayer (e.g., chaplain crouching beside a wheelchair). The physical motion of prayer could connect to an older person with dementia. One chaplain was particularly attuned to embodied dimensions: "Sometimes I'll do the Lord's prayer with hand motions ... we have a number of people who don't always know what's going on, can't hear very well, or don't speak English" (P2|S2). When Catholic volunteers came to visit residents, they often prayed with a rosary to engage with the embodied nature of prayer. A chaplain showed us a video-clip she had taken of a resident who was sitting in a withdrawn state of dementia and as hymn singing began, she participated and sang along. Reflecting the earlier concern to connect to the person and affirm human dignity, another chaplain emphasized the importance of touch during prayer, especially when praying with someone of a different faith or language: "I have recorded Sikh prayers and when there is a Sikh elder ... I have sat and held hands with the woman, and listened to the prayers with her" (P15|S11). Prayer, as a form of care, was not merely done through spoken words, but through presence and the whole of the body that is materially and sensory-attuned to and co-constituted with another.

\section{Motivations OF Prayer}

The participants interviewed were agents of prayer, which meant that prayer was influenced by their individual identities and motivations. Prayer was rarely described as for its own sake; rather prayer was usually offered with an aim in mind. Two key motivations for offering prayer emerged: therapeutic and pastoral. Therapeutic motivations referred to the desire of the chaplain to promote wellbeing through prayer. One chaplain stated, "... You want them to come away with a sense of hope and comfort. Someone has heard me ... and peace ... you can see it physically; the tension goes from their face" (P7|S5). It was also noted that prayer could help to decrease a patient's agitation or anxiety. One chaplain went up to a unit in 290 the late afternoon when people with dementia could be more agitated (a condition known as sun downing), to offer prayer as a calming intervention. Pastoral motivations referred to the intention of chaplains to support spiritual formation and honour the spiritual life of residents. Several participants described their job as "ministry." One participant equated his role with offering "spiritual food" to feed the spirits of the residents. He went on to say, "A person is made of a body, soul, and spirit. And how often is the spirit ministered to?" (P5|S4). This participant, a former pastor, brought this approach to his work as a chaplain, desiring to see spiritual growth in the residents he interacted with.

These motivations - therapeutic and pastoral — were shaped in part by the individual identities of the chaplains, including their personal beliefs and practices in regard to prayer itself. Several participants felt asking permission of the residents before praying was important saying, "You can't make an assumption that everybody's comfortable with that, with praying" ( $\mathrm{P} 7 \mid \mathrm{S} 5)$. One participant commented on the tension felt between attempting to make prayer hospitable to all residents, while protecting the sacredness of prayer. Maintaining integrity to one's own belief system was important to multiple participants, though expressed differently. For example, one chaplain felt comfortable incorporating multi-faith prayers in services, while another said:

If somebody wants to pray to Buddha I will invite Buddhist priest to come and they can pray to Buddha. I'm not going to. It's not who I am. And it would be, I think it would be an abuse of their faith as well as my own to pretend to be somebody I'm not. It's not authentic. (P9|S6)

Chaplains expressed a personal mandate motivating their work. One participant said, for example, "I mean we're God's body on earth, right? You know we're His hands. We're His feet. He can't hug my residents, I can. So, I do it in His name" (P9|S6). Here we see chaplains wanting to protect the sacredness of prayer, making prayer "hospitable" to all in an institution, believers and nonbelievers alike, while maintaining integrity to one's belief 
system.

\section{Organizational Support of Prayer}

Organizational mission and leadership approaches, and the material sites 325 that facilitated prayer (e.g., formal sacred spaces or chapels), along with each facility's spiritual care resources and policies all contributed to the social relations of prayer.

\section{MisSION AND LEADERSHIP}

In the residential care homes included in this study (both faith-affiliated and secular/public), prayer was observed as an institutional practice. Participants at both types of facilities were unanimous in viewing spiritual care services as integral to an organizational mission for person-centered care, supporting values of compassion, love, dignity, and respect. For example, one participant said,

Our role is supported by our values. [And those are] communicated to the entire staff whether they're Christian or not. This is what we stand for. So, don't be shocked when we pray over the meals or with the group in the living room. (P8|S5)

Often, the specific mission of each organization influenced opportunities for prayer. For example, some integrated daily prayer into communal activities for residents and staff, whereas other facilities permitted volunteers to create opportunities for prayer on a weekly basis. Our results suggest that the leadership determined how the chaplain's role was integrated into the rhythm of daily activities and the interdisciplinary team. For example, "I'm grateful that I'm on the management team because some chaplains wouldn't be included. People value what I do" (P2|S2). Combining pastoral and institutional work as a chaplain had positive and negative aspects, as did involvement in management duties. As one chaplain stated, "The administration has made it very helpful for us [and] has made it a priority for the chaplain to be involved. It does take away from my visitation time" (P2IS2). The mission and leadership of an institution often determined the resources for and the role of prayer in the day-to-day life of residential care.

\section{Material Sites}

One of the ways in which faith traditions were acknowledged was through formal and informal sacred services and spaces. Access to formal sacred space correlated with the provision of religious services/corporate prayer.

While only four of the facilities had formal sacred spaces, this did not exempt gatherings for religious services in other kinds of spaces that were informal 360 and multi-purpose. One of our participants explained how they used a lounge for services and prayer:

I do services in here once a week. It's quieter, more private. I'm able to pray for each person. I do a short service, sing a few songs. I might read from a picture book that helps people connect. (P2|S2)

Although these rooms could be busy with staff and carts going by, chaplains managed amid the profane to conjure the sacred, to set apart or make special (Taves, 2011). Other participants spoke about similar experiences of making prayer happen in informal spaces:

"Everybody can pray in any situation, anywhere" (P4|S4).

"One-to-one prayer in a resident's room is usually quite informal" (P8|S5).

"For me prayer is in the moment ... [staff] need it in the moment, whether we're standing in the middle of the hallway or whatever ..." (P7|S5).

Hallways, elevators, residents' rooms, and multipurpose spaces such as 380 lounges were found to be fluid and not correlated to physical religious spaces. One could perceive religious expressions as sidelined, replaced by "neutral" spaces and practices (e.g., TV, yoga, crafts). 
Alternatively, in these spaces - the dining room and the multipurpose room-prayer could be seen as endorsed by the institutional powers of the residential care home, and ritualized within it. Religious practices of prayer, singing, and reading of scriptures could temporarily mark a common space as sacred. Although most of the facilities were managed by faith-affiliated organizations, the visibility of religious images and symbols varied. Religious images were not prominent in the public spaces of most organizations with the exception of four faithbased institutions with strong cultural and religious ties. Sacred symbols were often found in the privacy of residents' rooms. Most residential care homes were hybrid spaces of institutionalized healthcare and home environs. While the institution erased religious symbols to create neutral spaces, some spaces were sacralized on occasion to allow for expressions of prayer, to bring the otherworldly into the mundane.

\section{Spiritual Care Resources and Policies}

Spiritual care resources and related policies differed among the organizations. Funding was incorporated into organizational budgets, endowed by private funding, or an amalgamation of both. The number of chaplaincy hours was seen to impact residents' opportunity to participate in prayer. Below are excerpts from participants who spoke about temporalities of prayer (i.e., the different times and timing of prayer, whether planned or spontaneous) and the administrative effects on this:

"To have a one-on-one, to have an actual half hour or 45-minute visit where you're actually touching the soul spiritually, praying with them, it becomes a healing process" (P5IS4).

"You have a 20-minute conversation with somebody. Can I pray for you before I go? And then you make a note of the things that have come up during the visit and you pray for those things" (P9IS6).

With limited resources for spiritual care, some residents received more prayer than others. Lack of regular access to chaplains was seen as a barrier to prayer: "Trying to find the time for everyone ... to do this job properly would be to see every single resident practically every day" (P1|S1). Another chaplain put it similarly: "I think what makes me feel disappointed is the rushing. We do not spend time to sit down, and even to pray" (P4IS4). The scarcity of resources left some participants feeling over-extended in their work. The facilities varied from not having any policies specific to prayer or spiritual care, to having very detailed policies. The participants in facilities with extensive policies spoke about the constraints of administrative duties, which took time away from residents. A participant explained their experience:

There's a policy for every single thing. For instance, prayer group has a program outline. That program outline is revised once a year; submitted to the administrator and then returned to me. Every single thing I do has a policy, has a procedure. This is why you do this, this is how you do it, and these are how you measure what you've done. ... I guess because health- care facilities have to cover themselves. It's become onerous and taken away time spent with residents. The administration has increased. (P9IS6)

This participant highlights the emphasis on achieving positive clinical outcomes for patients and residents in places of healthcare, including residential care homes. Chaplains at facilities with less explicit policies were still active in praying with residents, but expressed hesitancy about openness of these practices because of administrative oversight, as reflected in this comment: "As long as they're not micromanaging. I'm not going to tell them that I walk around praying and count that as work. But I still think it's important. They don't always share the same values" (P2IS2). Participating chaplains explained how they both resisted and yielded to administrative tensions within residential care.

Social Influences on Prayer in Residential Care

Along with the personal, interpersonal, and institutional influences on how prayer was 
expressed in residential care homes, the results also give insight 445 into the social influences more broadly that mediate expressions of prayer.

\section{Prayer In CONTEXTS OF Diversity}

The residential care homes represented by the participants had a range of diversity amongst the residents and staff, varying from the Jewish care home that was relatively homogeneous, to one care home that, though operated by a Christian denominational organization, had less than $5 \%$ of residents self-identifying with that particular denomination. The chaplain in this particular care home described it saying:

It's about 20 Chinese residents of the 75, and then it's really everything else, South Asian, a couple of ladies who are Spanish, some people are German, Russian, Malaysian. Very diverse, which is kind of nice. And the staff are also varied, a lot of Filipina, a lot of South Asian (Indian), and they are religiously varied too, some Christians, some Hindu. (P2|S2)

Diversity also involved language differences that could act as a barrier to offering spiritual support and prayer. One participant, however, felt that prayer in its various forms could be "versatile" and "useful" in connecting when there were linguistic differences: "in situations with language mismatch, prayer can be one of the most effective ways to minister to people, when having a conversation or taking a walk together is impossible, or reading Scripture is not helpful" (P2|S2). Social diversity included those who were nonreligious or nonpracticing, which in some cases represented the majority of the residents, as described by one participant: "for the most part people here don't really understand prayer. It's just the way our society's going. They have never walked in the door of a church in their lives" (P3|S3). This comment reflects the generational shift underway, with the trend away from religious affiliation and church attendance (NHS, 2011). Yet, even in cases of nonaffiliation and nonbelief, participants noted that prayer might take place: "prayer is universal. Prayer is not limited to only those who go to church" (P4|S4). In some situations, participants perceived entrenched, racialized influences. One participant, for example, described tensions in her neighborhood where Muslim citizens were newcomers, with rocks thrown through the mosque windows and explicit resistance from the established Christian community:

We're still in the adjustment period for the Muslim people. I've been at prayer retreats and have people pray against Muslims, called them demonic in prayers. I was not in favor of that. I don't believe the purpose of prayer is to ever pray against another human being. (P2|S2)

This same participant was asked whether they had other circumstances 485 where prayer had not been welcomed, to which she quickly replied: "Oh absolutely. A lot of residential school survivors are very leery of any spiritual intervention ... it's a love hate thing" (P15|S11). Here, the participant is referencing the historical injustices perpetrated against Indigenous peoples in Canada, where children were placed in church-run residential schools, 490 resulting in intergenerational trauma from the forced separation of children from their families, the denigration of Indigenous culture, and widespread emotional and sexual abuse.

\section{Politics of Permission}

This degree of diversity, including the resistances, placed participants in situations of needing to be responsive to multiple spiritual identities. They recognized that not everyone viewed or practiced prayer in the same way, and they were generally careful about not imposing prayer on others. They all described how they would seek permission to pray, and observed that most often people would happily accept prayer, with " $99.9 \%$ saying yes." One participant who worked in an area with many Indigenous people put it this way:

Sometimes I will say, 'if you don't mind I would like to pray for you. If people say 'yes', then I say, 'how are you most comfortable praying? What language do you use for our creator, the sacred, the divine source, spirit?' (P15|S11) 
Several commented that perhaps they were too cautious or "politically correct" in their approach. "In the beginning I was more cautious, too cautious, being very careful not to impose my belief system or my faith onto someone else" ( $\mathrm{P} 1 \mid \mathrm{S} 1)$. Conversely, some of the participants raised the possibility of being asked to pray in a way that might not fit with their own beliefs. One (Christian) participant talked about drawing prayers from a book of Baha'i prayers which she found aligned well with her perspective, but added that "it's so important to not do anything against our own beliefs or conscience" (P15|S11). She also drew on prayers posted on an Interfaith Council website, explaining "whenever I do a public prayer I make sure to learn and draw from what these websites advise." One situation in which prayer could be considered impositional was in relation to grace before meals. At two sites, prayer was said communally (formally) before every meal. A chaplain at one of these sites expressed reservation:

I go both ways about that. I see the benefit of having it, but sometimes I feel like there's something damaging to prayer when you have these formalized prayers that not everyone agrees with. I don't know. So far nobody's complained. (P2|S2)

At the second site, printed prayers were placed at each table and staff were to read these prayers as a way to handle awkwardness or resistance. A chaplain at a site where table grace was not formalized commented: "We don't pray at meals because we've got a wide variety of people. Some have no religion or faith ..." (P3|S3). In a few organizations, policy required that staff meetings began with prayer, resulting in a situation where prayer might be imposed on employees. Meetings higher in the organization (e.g., board meetings, managerial meetings) were more likely to start with formal prayers, whereas meetings closer to the pointof-care interpreted the mandate for prayer more broadly, and might offer an inspiring image or saying. Overall, most of the participants evidenced awareness in regard to when prayer might not be welcomed or coercive, both in one-on-one encounters and in corporate prayers.

\section{Religion in the Public Sphere}

The participants reflected on the broader matter of religion in the public sphere, with the interpretation that the faith-affiliated organizations they worked in were a form of the public sphere. While some of the organizations confidently embraced spiritual care and prayer, others were more cautious 545 when it came to the integration of faith into the public sphere. For the chaplains working at these faith-based sites, this meant there was also variation in how they viewed the place of religion in the public sphere. One participant noted that even though the organization was faith-based, "we work in the secular world. We have to respect their [those who are nonreligious] thinking, right?" (P4|S4). Another participant noted that the mere presence of a religiously-affiliated healthcare institution in a secular Canada was an anomaly saying, "it is interesting that we're even allowed to be Christian in Canada" (P2|S2). The participant attributed this presence to the historical founding of the institution, and the ongoing financial funding by the organization. For others, the presence and contributions of religious caregivers (professionals and volunteers) and faith-based organizations was unquestioned, reflecting the religiously plural make-up of Canadian society, the contributions of faith-based individuals and institutions, and the relevance of spiritual values, beliefs, and practice to elder care. One chaplain explained,

It's hard for me to separate the religious and the secular. Because I view those secular interactions as religious expression from my side ... emulating God being kind and caring for the other person. Even if they don't necessarily see things the same way. (P1|S1)

Another chaplain described an active group of diasporic Catholic volunteers who came regularly to pray with residents, a reminder that newcomers often come with strong ties to organized religion. In these ways, spiritual care and prayer could take religious or nonreligious forms, reflecting the diversity found within society.

\section{DISCUSSION}


The results of this study demonstrate the relevance of religion and spirituality to residential care, especially in faith-affiliated institutions, and illustrate how prayer functions as an opportunity for connection and understanding. Not surprisingly, prayer was predominantly viewed as theistic by the participants in this study; specifically, as a form of communication with the divine (i.e., God). Emergent definitions of prayer, particularly as they relate to prayers among the nonreligious (Drescher, 2016), are opening up the referent of prayer to be the sacred broadly, where the frame of reference is that which is beyond oneself and "in some sense 'sacred': higher, more powerful, more meaningful, more truthful, than everyday existence" (Woodhead, 2015, p. 228). The participants in this study, however, tended toward traditional definitions of prayer, likely reflecting their own spiritual views and also those of the cohort of older adults with whom they prayed. At this basic level of how prayer is understood, one sees the social character of prayer: that prayer is embedded in and reflects the social norms of the communities in which it is practiced (Genova, 2015; Giordan, 2015; Mason, 2013).

The social nature of prayer is also exemplified in the emphasis participants placed on prayer in the context of relationships. Rather than interpreting prayer as predominantly interior or individual, participants spoke to the exteriority of prayer. While collective, formal expressions during religious services were mentioned, the stronger emphasis was on interpersonal relationships that were seen to set the conditions for prayer, and also result from praying together. Although this type of relationality is not widely reported in the prayer literature, a strong emphasis on relationships is considered foundational to the provision of spiritual care as well as healthcare more generally (McCormick \& Hildebrand, 2015).

The paradoxical intimate and public nature of life in residential care homes-where all aspects of daily living are shared with strangers (Boris \& Parrenas, 2010)-brings these same qualities to prayer. The embodiment of prayer is well documented; as Giordan and Woodhead (2013) say, "it is the body itself that prays" (p. 2). With the findings of our study, we are tuning into how prayer might be part of the body memory for the recipients of prayer, especially those with dementia, where ritual and spiritual practices previously engaged were intentionally called out by the chaplains through prayer, with motivations of relational connection, affirmation of identity, and promotion of healing or wellbeing. Even frail bodies thus can serve as a "material site at the center of the production and consumption of religion" (Chidester in Valquez, 2011, p.11).

The organizational support for prayer evidenced in this study provides further insight into the social relations of prayer in residential care settings. Although few of the institutions represented in our study had policies specific to prayer or spiritual care, there was a sense that chaplains were enacting the intent of the institution as they prayed with residents. In sites where there were designated sacred spaces (i.e., chapels), this institutional tie was further strengthened. For the most part, however, the material sites of prayer could be understood as "liminal," as spaces between institutionalized care and intimate, personal everyday life (Collins, 2015; Reimer-Kirkham

et al., 2011).

Dynamics around difference played out in relation to prayer between people who hold differing faith traditions. Galek et al. (2010) reported that chaplains were more likely to pray along lines of religious concordance. In our study, participants too voiced hesitation when they reached across religious boundaries, which we interpreted against the background of broader social discourses about the place of religion in the public sphere. While some faithbased organizations confidently embraced spiritual care and prayer, others saw tensions between faith and healthcare in a secular culture. In Canada, the emerging understanding of secularization is not the absence of religion from meaningful influence in society, but rather a religiously plural landscape where secularizing trends co-exist with continued or even increasing influence in other spheres (Lefebvre \& Beaman, 2014). 
This study carries implications for chaplaincy in residential care settings. Chaplains are well positioned by their relational and supportive mandate to broker diversity for residents of faith and nonfaith. Prayer may be a site for such brokering and connecting. Chaplains are able to create formal and informal spaces and opportunities for prayer with residents, while being careful not to impose prayer. Facilitating prayer with frail residents, including those with dementia, may be important in providing spiritual support, communicating respect and dignity, and thereby affirming personhood. The study carries limitations due to the small sample size and specific geographic location, but these limitations are offset by the richness of data generated in relation to the expression of prayer in residential care homes. Given the paucity of research on prayer in such settings, our findings will need to be corroborated and expanded upon. Toward that end, the research team is currently conducting research in British and Canadian healthcare settings addressing the same question of how prayer is manifestwhether embraced, tolerated, or resisted - and how institutional and social contexts shape how prayer is understood and enacted.

\section{NOTES}

1. In this paper, we use the term "residential care" as is the common term in the region of this study. Synonymous terms are long-term care, care homes, and nursing homes.

2. In this article, we use the terminology of "chaplain", though in some of the residential care homes this role was referred to as a "spiritual care practitioner" or a "spiritual health practitioner."

3. Notation as follows: P refers to participant number, $\mathrm{S}$ refers to site number.

\section{REFERENCES}

Agli, O., Bailly, N., \& Ferrand, C. (2015). Spirituality and religion in older adults with dementia: A systematic review. International Psychogeriatrics, 27(5), 715-725. doi:10.1017/S1041610214001665

Ai, A. L., Ladd, K. L., Peterson, C., Shearer, M., \& Koenig, H. G. (2010). Long-term adjustment after surviving open-heart surgery: The effect of using prayer for coping replicated in a prospective design. The Gerontologist, 50(6), 798-809. doi:10.1093/geront/gnq046

Angus Reid Institute. (2016). Prayer: Alive and well in Canada. Retrieved from http://angusreid.org/prayer-in-canada

Boelens, P. A., Reeves, R. R., Replogle, W., \& Koenig, H. G. (2009). A randomized trial of the effect of prayer on depression and anxiety. International Journal of Psychiatry in Medicine, 39(4), 377-392. doi:10.2190/PM.39.4.c

Boris, E., \& Parrenas, R. (2010). Intimate labors: Cultures, technologies, and the politics of care. Stanford, CA: Stanford University Press.

Carr, T. J., Hicks-Moore, S., \& Montgomery, P. (2011). What's so big about the 'little things': A phenomenological inquiry into the meaning of spiritual care in dementia. Dementia, 10(3), 399-414. doi:10.1177/1471301211408122

Clark, A. (2010). Using walking interviews. Realities Toolkit \#13. ESRC National Centre for Research Methods. Retrieved July 19, 2017, from http:// www.socialsciences.manchester.ac.uk/morgancentre/realities/toolkits/walkinginterviews/13toolkit-walking-interviews.pdf

Collins, R. (2015). The micro-sociology of religion: Religious practices, collective and individual. Retrieved July 19, 2017 from www.thearda.com

Daaleman, T. P., Williams, C. S., Hamilton, V. L., \& Zimmerman, S. (2008). Spiritual care at the end of life in long-term care. Medical Care, 46(1), 85-91. doi:10.1097/MLR.0b013e3181468b5d

Davie, G. (2013). The sociology of religion: A critical agenda. London, UK: Sage.

Drescher, E. (2016). Choosing our religion: The spiritual lives of America's nones. New York, NY: Oxford University Press.

Elliot, H. (1997). The use of diaries in sociological research on health experience. Sociological Research Online, 2(2), 1-11. doi:10.5153/sro.38

Ennis, Jr, E. M., \& Kazer, M. W. (2013). The role of spiritual nursing interventions on improved outcomes in older adults with dementia. Holistic Nursing Practice, 27(2), 106-113. doi:10.1097/HNP.0b013e318280f7f9

Galek, K., Silton, N. R., Vanderwerker, L. C., Handzo, G. F., Porter, M., Montonye, M. G., \& Fleenor, D. W. (2010). To pray or not to pray: Considering gender and religious concordance in praying with the ill. Journal of Health Care Chaplaincy, 16(1-2), 42-52. doi:10.1080/08854720903529694 
Genova, C. (2015). Prayer as practice: An interpretive proposal. In G. Giordan \& L. Woodhead (Eds.), A sociology of prayer (pp. 9-24). Surrey, UK: Ashgate.

Gijsberts, M. J. H. E., van der Steen, J. T., Muller, M. T., Hertogh, C. M., \& Deliens, L. (2013). Spiritual end-of-life care in Dutch nursing homes: An ethnographic study. Journal of the American Medical Directors Association, 14(9), 679-684. doi:10.1016/j.jamda.2013.04.001

Giordan, G. (2015). Introduction: You never know. Prayer as enchantment. In G. Giordan \& L. Woodhead (Eds.), A sociology of prayer (pp. 1-8). Surrey, UK: Ashgate.

Giordan, G., \& Woodhead, L. (2013). Introduction: Prayer in religion and spirituality. In G. Giordan \& L. Woodhead (Eds.), Annual review of the sociology of religion: Volume 4: Prayer in religion and spirituality (pp. 1-8). Leiden, The Netherlands: Brill.

Hayward, R. D., \& Krause, N. (2013). Patterns of change in prayer activity, expectancies, and contents during older adulthood. Journal for the Scientific Study of Religion, 52(1), 17-34.

Hill, P. C., \& Pargament, K. I. (2008). Advances in the conceptualization and measurement of religion and spirituality: Implications for physical and mental health research. Psychology of Religion and Spirituality, S (1), 3-17. doi:10.1037/1941-1022.S.1.3

Hochschild, A. (2003). The managed heart: Commercialization of human feeling 20th Anniversary Edition. Los Angeles, CA: University of California Press.

James, W. (1890/1950). The principles of psychology. NY: Dover.

Krause, N., Chatters, L. M., Meltzer, T., \& Morgan, D. L. (2000). Using focus groups to explore the nature of prayer in late life. Journal of Aging Studies, 14(2),191-212.

Krause, N., \& Chatters, L. M. (2005). Exploring race differences in a multidimensional battery of prayer measures among older adults. Sociology of Religion, 66(1), 23-43.

Lefebvre, S., \& Beaman, L. G. (Eds.). (2014). Religion in the public sphere: Canadian case studies. Toronto, ON: University of Toronto Press.

Mason, M. (2013). Making the sacred real. In G. Giordan \& L. Woodhead (Eds.), Annual review of the sociology of religion: Volume 4: Prayer in religion and spirituality (pp. 9-26). Leiden, The Netherlands: Brill.

McCormick, S. C., \& Hildebrand, A. A. (2015). A qualitative study of patient and family Perceptions of chaplain presence during post-trauma care. Journal of Health Care Chaplaincy, 21(2), 6075. doi:10.1080/08854726.2015.1016317

National Household Survey (NHS). (2011). Religion, immigrant status and period of immigration, age groups and sex for the population in private households.

Author. Retrieved July 19, 2017, from: www12.statcan.bc.ca

Ødbehr, L. S., Kvigne, K., Hauge, S., \& Danbolt, L. J. (2015). Spiritual care to persons with Dementia in nursing homes; A qualitative study of nurses' and care workers' experiences. BMC Nursing, 14(1), 70. doi:10.1186/s12912-015-0122-6

Reimer-Kirkham, S., Sharma, S., Pesut, B., Sawatzky, R., Meyerhoff, H., \& Cochrane, M. (2011). Sacred spaces in public places: Religious and spiritual plurality in healthcare. Nursing Inquiry, 19(3), 202-212. doi:10.1111/j.1440-1800.2011.00571.x

Sampson, E. L., Gould, V., Lee, D., \& Blanchard, M. R. (2006). Differences in care received by Patients with and without dementia who died during acute hospital admission: A retrospective case note study. Age and Ageing, 35, 187-189. doi:10.1093/ageing/afj025

Sharma, S., Reimer-Kirkham, S., \& Cochrane, M. (2013). Prayer as transgression: Stories from healthcare. In G. Giordan \& L. Woodhead (Eds.), Annual review of the sociology of religion (pp. 189-204). Oxford, UK: Brill.

Sharp, S. (2012). For a social psychology of prayer. Sociology Compass, 6(7), 570-580.

Smith, L. G. (2008). Prayer as an intervention for agitation in dementia residents (Unpublished doctoral dissertation). The University of New Mexico, New Mexico.

Taves, A. (2001). Religious experience reconsidered: A building-block approach to the study of religion and other special things. Woodstock, Oxfordshire, UK: Princeton University Press.

Thorne, S. (2016). Interpretive description: Qualitative research for applied practice (2nd ed.). New York, NY: Taylor \& Francis.

Thorne, S., Reimer-Kirkham, S., \& MacDonald-Emes, J. (1997). Interpretive description: A noncategorical qualitative alternative for developing nursing knowledge. Research in Nursing \& Health, 20(2), 169-177. doi:10.1002/(SICI)1098-240

Valquez, M. (2011). More than belief: A materialist theory of religion. New York, NY: Oxford University Press.

Woodhead, L. (2015). Conclusion. Prayer as changing the subject. In G. Giordan \& L. Woodhead (Eds.), A sociology of prayer (pp. 213-230). Surrey, UK: Ashgate.

Worcester, S. (2008). Study probes the positive effects of prayer in nursing home residents with 
dementia. Caring for the Ages, 9(11), 18. 